\title{
Experimental and Theoretical Evaluation of Asymmetric Thioureas on the Corrosion of Carbon Steel in Acidic Medium
}

\author{
Arthur Valbon ${ }^{1}$, Marcelo. A. Neves ${ }^{2}$, Aurea Echevarria ${ }^{1, *}$ \\ ${ }^{1}$ Departamento de Química, Instituto de Ciências Exatas, Universidade Federal Rural do Rio de \\ Janeiro, 23890-000, Seropédica - Rio de Janeiro, Brasil \\ ${ }^{2}$ Departamento de Física, Instituto de Ciências Exatas, Universidade Federal Rural do Rio de Janeiro, \\ 23890-000, Seropédica - Rio de Janeiro, Brasil \\ *E-mail: echevarr@ufrrj.br
}

doi: $10.20964 / 2017.04 .55$

Received: 25 January 2017 / Accepted: 23 February 2017 / Published: 12 March 2017

\begin{abstract}
The inhibitory effects of $N$-( $p$-X-phenyl)- $N$ '-benzyl-thiourea (THIOB1 and THIOB2) and $N$-( $p$-Xphenyl)- $N$ '-phenethyl-thiourea (THIOF1 and THIOF2) on the corrosion of AISI 1020 carbon steel in 1 mol L ${ }^{-1} \mathrm{HCl}$ were evaluated by polarization curves (PP), Linear Polarization Resistance (LPR), Electrochemical Impedance Spectroscopy (EIS) and molecular modeling. The corrosion inhibition efficiency of phenetyl-thioureas slightly exceeded that observed for benzyl-thioureas; also, all thioureas acted as mixed inhibitors. 98\% was the maximum anticorrosion efficiency for THIOF2, obtained by LPR. The adsorption of the evaluated inhibitors followed Langmuir isotherm. Theoretical results were corroborated by experimental data that showed phenetyl-thioureas were slightly better corrosion inhibitors than benzyl-thioureas.
\end{abstract}

Keywords: Carbon steel, Polarization, EIS, Modeling studies, Acid corrosion

\section{FULL TEXT}

(C) 2017 The Authors. Published by ESG (www.electrochemsci.org). This article is an open access article distributed under the terms and conditions of the Creative Commons Attribution license (http://creativecommons.org/licenses/by/4.0/). 